\title{
PENYEBARAN JENIS JIRAK (Symplocos fasciculata Zoll.) DI RESORT KAWAH RATU TAMAN NASIONAL GUNUNG HALIMUN SALAK, JAWA BARAT
}

\author{
Distribution Of Jirak (Symplocos fasciculata Zoll.) Types In The Resort Of Ratu Crater National \\ Park Of Mount Halimun Salak, West Java
}

\section{Iwan Hilwan $^{1 *}$ dan Irvan Aldi Perdana Wiraatmadja ${ }^{2}$}

(Ditrerima Maret 2021/Disetujui April 2021)

\begin{abstract}
Jirak (Symplocos fasciculata Zoll.) is one of the native species in the Gunung Halimun Salak National Park, especially in the Kawah Ratu resort. This plant can be used as a natural coloring agent, in addition to plant parts such as leaves can also be eaten and used as medicine. Because of the benefits of jirak, this plant is considered important to be cultivated. This study aims to analyze the density and distribution pattern of jirak (Symplocos fasciculata Zoll.) at Kawah Ratu Resort, Gunung Halimun Salak National Park. Data collection was carried out in two blocks located at the Kawah Ratu Resort of Mount Halimun Salak National Park, namely the Leles block and the Pamengpeuk block using the single plot method. The results showed that jirak distribution pattern in the two observation blocks was grouped.
\end{abstract}

Keywords: Distribution, Jirak, Kawah Ratu Resort, Symplocos fasciculata Zoll., Gunung Halimun Salak National Park

\section{PENDAHULUAN}

Hutan adalah kawasan yang didominasi oleh pepohonan dan jenis tumbuhan lainnya. Menurut Undang-undang Nomor 41 tentang Kehutanan tahun 1999, hutan adalah suatu kesatuan ekosistem berupa hamparan lahan berisi sumber daya alam hayati yang didominasi pepohonan dalam persekutuan alam lingkungannya yang satu dengan yang lainnya tidak dapat dipisahkan. Hutan pegunungan atau hutan montana adalah hutan yang terdapat di daerah pegunungan dengan ketinggian lebih dari $1000 \mathrm{~m} \mathrm{dpl}$, hutan ini merupakan salah satu formasi dari hutan tropika basah, dan berdasarkan ketinggiannya dapat dibagi lagi menjadi beberapa jenis.

Kawasan Taman Nasional Gunung Halimun Salak (TNGHS) mewakili beberapa tipe hutan yang ada di Indonesia, antara lain hutan hujan dataran rendah, hutan sub montana, dan hutan montana. Kawasan TNGHS ini memiliki keanekaragaman hayati yang tinggi dan sekaligus menjamin keberlangsungan fungsi hidrologi di Kabupaten Bogor, Lebak, dan Sukabumi (Carolyn et al. 2013).

Salah satu jenis yang cukup banyak ditemukan di kawasan Taman Nasional Gunung Halimun Salak adalah jirak/loba (Symplocos fasciculata Zoll.) yang termasuk ke dalam suku/famili Symplocaceae. Tumbuhan ini memiliki potensi untuk dijadikan bahan pewarna alami. Zat pewarna ini dapat ditemui pada bagian dalam kulit batangnya dan daun (Hanum 2012). Oleh masyarakat

\footnotetext{
${ }^{1}$ Dosen Departemen Silvikultur, Fakultas Kehutanan dan

Lingkungan, IPB University

* Penulis korespondensi:

e-mail: ihilwan@yahoo.co.id

${ }^{2}$ Mahasiswa Departemen Silvikultur, Fakultas Kehutanan

dan Lingkungan, IPB University
}

sekitar sering kali dimanfaatkan sebagai mordant (pengikat zat warna agar tidak larut dalam air) pada pewarnaan kain tenun tradisional (Pamungkas 2013). Beberapa jenis S. Fasciculata juga diketahui dapat berfungsi sebagai obat dengan memakan langsung daunnya atau dikukus terlebih dahulu (Lemmens dan Wulijarni 1999). Melihat banyaknya manfaat serta potensi yang dimiliki oleh tanaman jirak menjadikan penelitian ini penting dilakukan untuk mengetahui potensi kelimpahan jirak dengan mengetahui kerapatan dan pola penyebaran jirak. Penelitian ini bertujuan menganalisis kerapatan dan pola penyebaran jenis jirak (S. fasciculata) di Taman Nasional Gunung Halimun Salak. Hasil penelitian ini diharapkan dapat memberikan manfaat berupa data dan informasi mengenai kerapatan dan pola penyebaran jenis jirak, serta kondisi lingkungan di Resort Kawah Ratu Taman Nasional Gunung Halimun Salak.

\section{METODE PENELITIAN}

\section{Waktu dan Tempat Penelitian}

Penelitian dilaksanakan pada bulan Januari 2021 di Resort Kawah Ratu Taman Nasional Gunung Halimun Salak, Sukabumi, Jawa Barat.

\section{Alat dan Bahan}

Alat yang digunakan dalam penelitian ini terdiri dari pita meter, pita ukur (phiband), haga hypsometer, tali rafia, tali tambang, kompas, golok, tally sheet, kamera, buku lapangan, alat tulis, dan laptop yang memiliki perangkat lunak Sexi-Fs, Microsoft Word dan Microsoft Excel. Bahan utama yang digunakan adalah tegakan 
hutan di Resort Kawah Ratu Taman Nasional Gunung Halimun Salak, Sukabumi, Jawa Barat.

\section{Tahapan Penelitian}

\section{Tahap Persiapan}

Tahap persiapan dilakukan meliputi beberapa kegiatan, di antaranya survei lokasi penelitian, pengurusan izin lokasi penelitian, persiapan peralatan dan bahan yang digunakan untuk pengambilan data di lapangan serta pengumpulan data sekunder atau literatur terkait penelitian yang dilakukan.

\section{Jenis Data yang Dikumpulkan}

Data yang dikumpulkan berupa data primer dan data sekunder. Data primer merupakan data yang langsung dikumpulkan di lapangan dengan menggunakan metode analisis vegetasi. Teknik analisis vegetasi bertujuan untuk mengetahui komposisi jenis serta struktur vegetasi dengan mengambil data vegetasi tingkat semai, pancang, tiang dan pohon. Data yang diambil berupa nama jenis, jumlah individu per jenis, diameter batang, tinggi total, tinggi bebas cabang, serta tutupan tajuk. Data sekunder yang dikumpulkan berupa wawancara, studi pustaka, dan informasi lain terkait kondisi umum lapangan yang meliputi, sejarah kawasan, letak, luas, kondisi tanah, topografi, iklim, dan kondisi vegetasi.

\section{Analisis Vegetasi}

Penelitian data lapangan dilakukan dengan menggunakan teknik analisis vegetasi berupa petak tunggal berukuran $100 \mathrm{~m}$ x $100 \mathrm{~m}$. Petak tunggal tersebut dibagi menjadi sub petak sebanyak 25 sub petak. Terdapat 2 blok hutan yang akan diamati dengan masingmasing dibuat 1 petak tunggal $100 \mathrm{~m}$ x $100 \mathrm{~m}$. Metode pengambilan data yang dilakukan untuk analisis vegetasi disajikan pada Gambar 1.

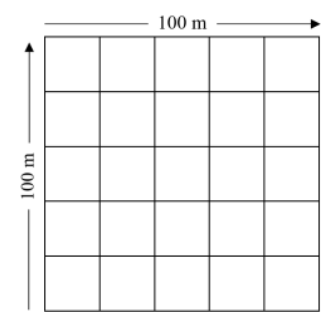

Gambar 1 Petak tunggal analisis vegetasi

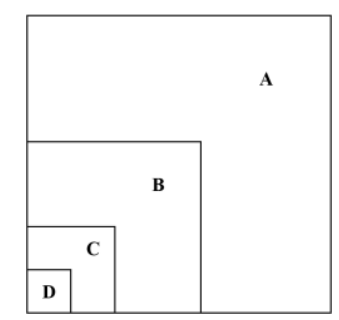

Keterangan: Ilustrasi metode pengambilan data untuk analisis vegetasi (A) petak $20 \mathrm{~m}$ x $20 \mathrm{~m}$ untuk pengamatan tingkat pohon, (B) petak $10 \mathrm{~m}$ x $10 \mathrm{~m}$ untuk pengamatan tingkat tiang, (C) petak $5 \mathrm{~m}$ x $5 \mathrm{~m}$ untuk pengamatan tingkat pancang dan (D) petak $2 \mathrm{~m}$ x 2 m untuk pengamatan tingkat semai dan tumbuhan bawah.

\section{Analisis Data}

\section{Indeks Nilai Penting}

Struktur dan komposisi vegetasi merupakan suatu hal yang perlu diketahui untuk mendapatkan INP. Maka, setiap petak ukur harus dilakukan pengukuran analisis dominansi, frekuensi, dan kerapatan untuk setiap jenis tumbuhan. Menurut Anggana et al. (2019) Perhitungan dilakukan dengan menggunakan rumus sebagai berikut:

a. Kerapatan suatu jenis (K) (ind/ha)

$$
\mathrm{K}=\frac{\sum \text { individu suatu jenis }}{\text { Luas petak contoh }}
$$

b. Kerapatan relatif suatu jenis (KR) (\%)

$$
\mathrm{KR}=\frac{\mathrm{K} \text { suatu jenis }}{\mathrm{K} \text { semua jenis }} \times 100 \%
$$

c. Frekuensi suatu jenis $(\mathrm{F})$

$$
\mathrm{F}=\frac{\sum \text { sub petak ditemukan }}{\sum \text { seluruh sub petak contoh }}
$$

d. Frekuensi relatif suatu jenis (FR) (\%)

$$
\mathrm{FR}=\frac{\mathrm{F} \text { suatu jenis }}{\mathrm{F} \text { semua jenis }} \times 100 \%
$$

e. Dominansi suatu jenis (D) $\left(\mathrm{m}^{2} / \mathrm{ha}\right)$ untuk pohon

$$
\mathrm{D}=\frac{\text { Luas bidang dasar suatu jenis }}{\text { Luas petak contoh }}
$$

f. Dominasi relatif suatu jenis (DR)

$$
\mathrm{DR}=\frac{\mathrm{D} \text { suatu jenis }}{\mathrm{D} \text { semua jenis }} \times 100 \%
$$

\section{Indeks Keanekaragaman Jenis}

Keanekaragaman jenis (species diversity) dihitung dengan rumus indeks Shannon-Wiener (H') berdasarkan Ludwig and Reynolds (1988) dalam Tudjuka et al. (2014):

$$
\mathrm{H}^{\prime}=-\sum_{i=1}^{n}\left(\left(\frac{n i}{N}\right) \ln \left(\frac{n i}{N}\right)\right)
$$

Keterangan:

$\mathrm{H}^{\prime}=$ indeks keanekaragaman jenis Shannon

ni $=$ nilai kerapatan jenis ke-i

$\mathrm{N}=$ total kerapatan semua jenis

Nilai $H^{\prime}<2$ mengindikasikan bahwa keragaman jenisnya sedikit atau rendah, jika $\mathrm{H}^{\prime}=2-3$ keragaman jenisnya tergolong sedang, sedangkan jika nilai $\mathrm{H}^{\prime}>3$ menandakan keragaman jenis pada lokasi tersebut melimpah.

\section{Indeks Kekayaan Jenis}

Analisis kekayaan jenis dalam suatu plot ukur, bisa dihitung dengan pendekatan Indeks kekayaan jenis Margaleft. Adapun persamaan sebagai berikut:

Keterangan:

$$
\mathrm{R}=\frac{\mathrm{S}-1}{\ln (\mathrm{N})}
$$

$\mathrm{R}=$ indeks kekayaan jenis

$\mathrm{S}=$ jumlah jenis yang ditemukan

$\mathrm{N}=$ jumlah total individu 
Nilai kekayaan jenis ini dibagi kedalam tiga kategori yaitu rendah $(\mathrm{R}<3,5)$, sedang $(3,5<\mathrm{R}<5,0)$ dan tinggi $(\mathrm{R}>5,0)$ (Magurran 1988).

\section{Indeks Kemerataan Jenis (H')}

Indeks kemerataan jenis dapat diperoleh dengan rumus:

Keterangan:

$$
E=\frac{H^{\prime}}{\ln (S)}
$$

$\mathrm{E}=$ indeks kemerataan jenis

$\mathrm{S}=$ jumlah jenis yang ditemukan

$\mathrm{H}^{\prime}=$ indeks keanekaragaman jenis

Nilai kemerataan memiliki rentang antara 0-1, jika nilai indeks yang diperoleh mendekati satu berarti penyebarannya semakin merata. Nilai $\mathrm{E}<0,3$ menandakan kemerataan jenis rendah, nilai $\mathrm{E}$ dengan rentang 0,3-0,6 menandakan kemerataan jenis sedang, dan nilai $E>0,6$ menandakan kemerataan jenis tinggi (Ismaini et al. 2015).

\section{Indeks Dominansi Jenis $(C)$}

Indeks Dominansi (C) Indeks Dominansi dihitung dengan menggunakan rumus indeks dominanasi dari Simpson berdasarkan Odum (1993) dalam Sirait et al. (2018):

$$
\mathrm{C}=\left(\sum_{\mathrm{i}}^{\mathrm{n}}\left(\frac{\mathrm{ni}}{\mathrm{N}}\right)\right)^{2}
$$

Keterangan:

$$
\begin{array}{ll}
\mathrm{D} & =\text { Indeks Dominansi Simpson } \\
\mathrm{Ni} & =\text { Jumlah Individu tiap spesies } \\
\mathrm{N} & =\text { Jumlah Individu seluruh spesies }
\end{array}
$$

Indeks dominansi berkisar antara 0 sampai 1, dimana semakin kecil nilai indeks dominansi maka menunjukkan bahwa tidak ada spesies yang mendominasi, dan berlaku sebaliknya (Sirait et al. 2018).

\section{Indeks Penyebaran Morisita (IM)}

Pola sebaran spasial suatu spesies dapat diidentifikasi dengan menggunakan berbagai macam indeks sebaran, salah satu di antaranya adalah menggunakan Indeks Morisita dan Standarisasi Indeks Morisita (Rani 2003). Pola penyebaran jirak dapat diketahui dengan tahapan perhitungan sebagai berikut :

1. Menghitung nilai indeks Morisita (I $\delta$ ) (Morisita 1959):

Keterangan :

$$
\mathrm{I} \delta=n \frac{\left(\sum x i^{2}-\sum x i\right)}{\left(\sum x i\right)^{2}-\sum x i}
$$

I $\delta=$ indeks penyebaran Morisita

$\mathrm{n}=$ jumlah plot

$\sum x i=$ jumlah individu tiap plot

$\sum \mathrm{xi}^{2}=$ jumlah individu kuadrat tiap plot

2. Menghitung Mu dan Mc (Jongjitvimol et al. 2005):

$$
\begin{aligned}
& \mathrm{Mu}=\frac{\mathrm{X}^{2} 0.975-n+\sum x i}{\left(\sum x i\right)-1} \\
& \mathrm{Mc}=\frac{\mathrm{X}^{2} 0.025-n+\sum x i}{\left(\sum x i\right)-1}
\end{aligned}
$$

Keterangan :

$\mathrm{Mu}=$ indeks penyebaran Morisita untuk pola sebaran seragam

$\mathrm{X}^{2} 0.975=$ nilai chi-square tabel dengan derajat bebas $\mathrm{n}-$ 1 dan selang kepercayaan $97.5 \%$

Mc = indeks penyebaran Morisita untuk pola sebaran mengelompok

$\mathrm{X}^{2} 0.025=$ nilai chi-square tabel dengan derajat bebas $\mathrm{n}$ 1 dan selang kepercayaan $2.5 \%$

3. Menghitung Standar derajat Morisita (Jongjitvimol et al. 2005):

$$
\begin{array}{ll}
\text { Ip }=0.5+0.5\left(\frac{I \delta-M c}{n-M c}\right) & ; \text { jika I } \geq \geq \mathrm{Mc}>1.0 \\
\text { Ip }=0.5\left(\frac{\mathrm{I} \delta-1}{\mathrm{Mc}-1}\right) & ; \text { jika } \mathrm{Mc}>\mathrm{I} \delta \geq 1.0 \\
\mathrm{Ip}=-0.5\left(\frac{\mathrm{I} \delta-1}{\mathrm{Mu}-1}\right) & ; \text { jika } 1.0>\mathrm{I} \delta \geq \mathrm{Mu} \\
\mathrm{Ip}=-0.5+0.5\left(\frac{\mathrm{I} \delta-\mathrm{Mu}}{\mathrm{Mu}}\right) & ; \text { jika } 1.0>\mathrm{Mu} \geq \mathrm{I} \delta
\end{array}
$$

\section{HASIL DAN PEMBAHASAN}

\section{Komposisi Jenis Tanaman}

Jenis tumbuhan yang ditemukan di kawasan Resort Kawah Ratu berbeda-beda pada setiap lokasi blok pengambilan data. Ditemukan 99 jenis tumbuhan pada dua blok pengamatan. Jumlah jenis yang ditemukan pada dua blok pengamatan pada setiap tingkat pertumbuhan ditunjukkan pada Tabel 1 .

Tabel 1 menunjukkan bahwa pada kedua blok memiliki tingkat pertumbuhan dengan jumlah jenis yang bervariasi. Secara umum jumlah jenis terkecil terdapat pada tingkat pertumbuhan semai dan pancang, hal ini mungkin disebabkan tanaman mengalami gangguan pada tingkat pertumbuhan semai dan pancang sehingga mati sebelum menjadi pohon. Dapat dilihat pada tabel bahwa kedua blok yang diamati memiliki jumlah jenis pohon cukup banyak, ini dapat mengurangi intensitas cahaya karena tertutup oleh tajuk sehingga mengganggu pertumbuhan semai terutama jenis intoleran yang sangat membutuhkan cahaya.

Nilai kerapatan jenis jirak terbesar ada pada tingkat pertumbuhan semai dan pancang tetapi menurun drastis pada tingkat tiang dan pohon. Hal ini sesuai dengan penelitian Irfani (2016), bahwa hubungan antara kerapatan dengan tingkat pertumbuhan cenderung memiliki grafik dengan kurva seperti "J" terbalik, ini berarti meningkatnya ukuran individu berbanding lurus dengan menurunnya jumlah individu tersebut. Ini merupakan hal yang umum ditemui di hutan alam, tanaman akan beregenerasi dan membentuk anakan baru

Tabel 1 Jumlah jenis tumbuhan pada dua blok pengamatan

\begin{tabular}{llcc}
\hline \multirow{2}{*}{ No } & Tingkat & \multicolumn{2}{c}{ Jumlah Jenis } \\
\cline { 3 - 4 } & Pertumbuhan & Pamengpeuk & Leles \\
\hline 1 & Tumbuhan bawah & 24 & 23 \\
2 & Semai & 13 & 6 \\
3 & Pancang & 12 & 12 \\
4 & Tiang & 19 & 11 \\
5 & Pohon & 34 & 13 \\
\hline
\end{tabular}


namun banyak yang mati terlebih dahulu sebelum menjadi pohon karena persaingan untuk mendapatkan cahaya, persaingan antar jenis, dan faktor lainnya. Namun pada Blok Leles hanya ditemukan beberapa jirak pada tingkat pertumbuhan pancang dan tiang, ini disebabkan Blok Leles merupakan kawasan yang telah mengalami perambahan dan kemudian ditanami dengan jenis puspa. Jenis jirak yang ditemukan pada Blok Leles mungkin berasal dari biji yang terbawa oleh faktor seperti erosi tanah ataupun aliran air karena Blok Leles ini berlokasi di ketinggian yang lebih rendah dibandingkan Blok Pamengpeuk. Tabel 2 menyajikan kerapatan jenis jirak dengan jenis lainnya.

Indeks nilai penting menunjukkan tingkat penguasaan dari suatu jenis terhadap jenis-jenis lain dalam suatu komunitas (Mueller-Dombois dan Ellenberg 1974). Pergeseran nilai INP sangat dipengaruhi oleh penambahan atau pengurangan jumlah jenis tersebut. Jenis tumbuhan yang memiliki nilai INP tertinggi di lokasi penelitian tersaji pada Tabel 3.

Jenis jirak ( . fasciculata) merupakan jenis dominan pada tingkat semai di Blok Pamengpeuk dengan nilai INP sebesar $40,11 \%$. Jirak juga termasuk ke dalam tiga besar jenis dengan INP tertinggi pada tingkat pancang baik pada Blok Leles maupun Blok Pamengpeuk dengan nilai INP masing-masing sebesar $28,7 \%$ dan $27,62 \%$. Nilai
INP tertinggi di Blok Pamengpeuk pada tingkat semai adalah Tepus (Achasma megalacheios) sebesar 39,70\%. Pada tingkat pancang jenis dengan INP tertinggi adalah Saninten (Castanopsis Argentea) sebesar 36,76\%. Tingkat tiang didominasi oleh jenis Beleketebe, sedangkan pada tingkat pohon jenis yang mendominasi adalah Mumuncangan dengan INP sebesar $62,01 \%$. Kawasan Blok Leles sebagian besar didominasi oleh jenis Puspa dengan pengecualian pada tingkat tumbuhan bawah didominasi oleh jenis Rane (Selaginella unsinata) dengan INP sebesar 58,65\%. Tingkat semai, pancang, tiang, dan pohon di Blok Leles didominasi oleh jenis Puspa (Schima waliichii) dengan nilai INP berturut-turut sebesar $110,51 \%, 55,24 \%, 243,32 \%$, dan $218,18 \%$. Tiga besar tumbuhan dengan INP tertinggi disajikan pada Tabel 3. Hasil perhitungan pada tabel 4 menunjukkan bahwa nilai H' di sebagian besar lokasi adalah sedang, ini menandakan bahwa ekosistem hutan tersebut relatif lebih stabil dan terpelihara dibandingkan dengan komunitas hutan dengan nilai $\mathrm{H}^{\prime}$ yang lebih rendah (Krebs 1978).

Nilai R (indeks kekayaan) terbesar terdapat pada pohon di Blok Pamengpeuk. Hal ini merupakan hal yang wajar mengingat Blok pamengpeuk adalah hutan primer yang belum mengalami gangguan atau perambahan. Sementara pada Blok Leles dapat dilihat nilai $\mathrm{R}$ untuk

Tabel 2 Kerapatan jenis jirak dan non jirak di lokasi penelitian

\begin{tabular}{|c|c|c|c|c|c|}
\hline \multirow[b]{2}{*}{ No } & \multirow{2}{*}{$\begin{array}{l}\text { Tingkat } \\
\text { Pertumbuhan }\end{array}$} & \multicolumn{2}{|c|}{ Blok Pamengpeuk } & \multicolumn{2}{|c|}{ Blok Leles } \\
\hline & & Jirak (ind/ha) & $\begin{array}{l}\text { Non Jirak } \\
\text { (Ind/ha) }\end{array}$ & Jirak (ind/ha) & $\begin{array}{c}\text { Non Jirak } \\
\text { (Ind/ha) }\end{array}$ \\
\hline 1 & Semai & 1500 & 5300 & - & 2300 \\
\hline 2 & Pancang & 1500 & 928 & 112 & 768 \\
\hline 3 & Tiang & 144 & 84 & 4 & 1408 \\
\hline 4 & Pohon & 4 & 109 & - & 128 \\
\hline
\end{tabular}

Tabel 3 Jenis tumbuhan dengan INP tertinggi di lokasi penelitian

\begin{tabular}{|c|c|c|c|c|}
\hline $\begin{array}{l}\text { Tingkat } \\
\text { pertumbuhan }\end{array}$ & Blok Pamengpeuk & $\operatorname{INP}(\%)$ & Blok Leles & $\operatorname{INP}(\%)$ \\
\hline \multirow{3}{*}{ Tumbuhan Bawah } & $\begin{array}{l}\text { Achasma } \\
\text { megalacheios }\end{array}$ & 39,70 & Selaginella unsinata & 58,65 \\
\hline & Ludwigia octalvis & 33,43 & Clidemia hirta & 48,02 \\
\hline & Begonia glabra & 30,85 & $\begin{array}{l}\text { Ammomum } \\
\text { compactum }\end{array}$ & 16,35 \\
\hline \multirow{3}{*}{ Semai } & $\begin{array}{l}\text { Symplocos } \\
\text { fasciculata }\end{array}$ & 40,11 & Schima walichii & 110,51 \\
\hline & $\begin{array}{l}\text { Urophyllum } \\
\text { arboreum }\end{array}$ & 24,38 & $\begin{array}{l}\text { Symplocos } \\
\text { cochinchinensi }\end{array}$ & 25,72 \\
\hline & $\begin{array}{l}\text { Daphiniphylum } \\
\text { glaucescens }\end{array}$ & 20,93 & $\begin{array}{l}\text { Elocarpus } \\
\text { floribundus }\end{array}$ & 17,03 \\
\hline \multirow{3}{*}{ Pancang } & $\begin{array}{l}\text { Castanopsis } \\
\text { argentea }\end{array}$ & 36,73 & Schima walichii & 55,24 \\
\hline & Ostodes paniculata & 31,28 & $\begin{array}{l}\text { Calliandra } \\
\text { calothyrsus }\end{array}$ & 44,49 \\
\hline & $\begin{array}{l}\text { Symplocos } \\
\text { fasciculata }\end{array}$ & 28,47 & $\begin{array}{l}\text { Symplocos } \\
\text { fasciculata }\end{array}$ & 27,62 \\
\hline \multirow{3}{*}{ Tiang } & Sloanea sigun & 33,61 & Schima walichii & 243,32 \\
\hline & Ostodes paniculata & 28,61 & Machilus rimota & 11,85 \\
\hline & Piper anducum & 21,35 & Syzygium amieuense & 8,71 \\
\hline \multirow{3}{*}{ Pohon } & Ostodes paniculata & 62,01 & Schima walichii & 218,18 \\
\hline & $\begin{array}{l}\text { Castanopsis } \\
\text { argentea }\end{array}$ & 43,23 & Persea americana & 18,54 \\
\hline & $\begin{array}{l}\text { Dysoxylum } \\
\text { excelsum }\end{array}$ & 37,23 & Trema orientalis & 12,21 \\
\hline
\end{tabular}


tingkat tiang dan pohon sangat rendah, ini disebabkan blok leles memang ditanami dan didominasi oleh jenis Puspa, akan tetapi untuk tingkat semai dan pancang nilai R-nya masuk ke dalam kategori sedang yang berarti sudah mulai ada jenis-jenis baru yang masuk ke kawasan ini.

Hasil perhitungan selanjutnya menunjukkan bahwa nilai kemerataan jenis bervariasi dari 0,16-0,76. Menurut Ismaini et al. (2015), nilai kemerataan digolongkan sebagai berikut : nilai $\mathrm{E}<0.3$ tergolong rendah, nilai 0.3 $\leq \mathrm{E}<0.6$ tergolong sedang, dan nilai $\mathrm{E} \geq 0.6$ tergolong tinggi. Blok Pamengpeuk memiliki nilai kemerataan (E) yang tergolong tinggi untuk setiap tingkat, nilai kemerataan yang tinggi menandakan tidak adanya dominansi jenis dalam suatu komunitas hutan. Hal demikian tidak ditemukan pada Blok Leles melainkan hanya tingkat semai saja yang memiliki nilai kemerataan tinggi. Ini disebabkan pada Blok Leles jenis tanaman yang mendominasi adalah jenis Puspa.

Indeks dominansi (C) dapat menunjukkan pemusatan dan penyebaran jenis yang dominan, nilai indeks dominansi berkisar antara 0 sampai 1. Apabila didapatkan nilai indeks dominansi mendekati satu (1) maka komunitas hutan tersebut dipusatkan pada satu jenis, sedangkan jika nilai indeks dominansi mendekati angka nol (0) maka komunitas hutan tersebut didominasi secara bersama-sama (Gustani 2015).

Blok Pamengpeuk memiliki indeks dominansi yang bernilai rendah pada semua tingkat pertumbuhan, yang berarti tidak ada pemusatan atau penguasaan jenis tertentu. Indeks dominansi pada Blok Leles juga bernilai rendah untuk tingkat semai dan pancang, sedangkan untuk tingkat tiang dan pohon bernilai tinggi atau mendekati 1. Ini merupakan hal yang wajar sebagaimana diketahui Blok Leles sangat didominasi oleh jenis puspa.

\section{Pola Penyebaran Jirak}

Indeks morisita adalah parameter kualitatif yang akan menunjukkan pola penyebaran jenis tumbuhan pada suatu komunitas hutan. Indeks ini dapat membantu dalam menentukan metode apa yang paling cocok untuk memperkirakan kepadatan atau kelimpahan suatu populasi (Istomo dan Afnani 2014). Jenis jirak ( $S$. fasciculata) memiliki pola persebaran yang mengelompok baik pada Blok Pamengpeuk maupun Blok Leles. Menurut Istomo (1994), pola persebaran mengelompok merupakan hal yang umum terjadi di hutan alam. individu pohon akan mengelompok di suatu tempat tertentu karena terdapat keuntungan pada area tersebut baik dari lingkungan maupun dari interaksi antar individu di dalamnya. Pola persebaran jirak pada Blok Leles juga termasuk dalam kategori mengelompok walaupun area ini merupakan area yang ditanami jenis puspa. Ini menandakan jenis jirak telah menemukan kondisi yang menguntungkan di Blok Leles untuk ditumbuhi. Pola penyebaran jirak disajikan dalam Tabel 5 .

\section{Struktur Tegakan}

\section{Struktur Horizontal}

Struktur horizontal tegakan hutan dapat dilihat dengan menggabungkan kelas diameter dengan kerapatan pohon per hektar. Struktur horizontal dari kedua lokasi penelitian dapat dilihat dalam Gambar 3 yang menunjukkan bahwa kelas diameter 20-30 cm memiliki nilai kerapatan tertinggi di kedua blok pengamatan. Terdapat perbedaan yang jelas apabila melihat keseluruhan kelas diameter. Pada blok Pamengpeuk nilainya menurun namun kembali meningkat pada kelas diameter $>60$. Ini merupakan kaidah umum hutan alam dimana kurva akan cenderung membentuk "J" terbalik jika kondisi hutannya tidak atau

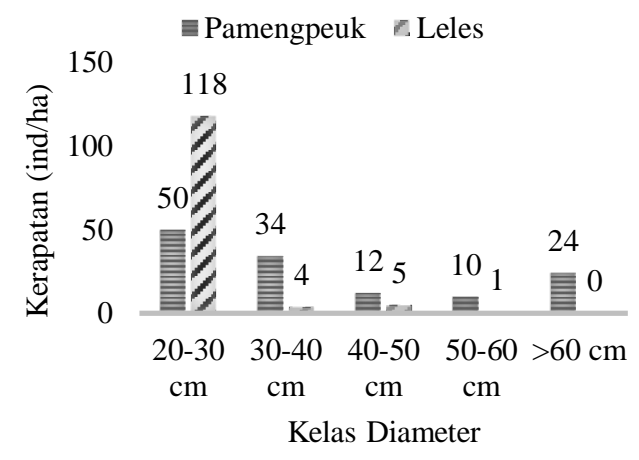

Gambar 3 Struktur horizontal pada tingkat pohon di lokasi penelitian

Tabel 4 Nilai H',R, E, dan C di lokasi

\begin{tabular}{|c|c|c|c|c|c|c|c|c|c|}
\hline Lokasi & $\begin{array}{l}\text { Tingkat } \\
\text { Pertumbuhan }\end{array}$ & $\mathrm{H}^{\prime}$ & Ket & $\mathrm{R}$ & Ket & $\mathrm{E}$ & Ket & $\mathrm{C}$ & Ket \\
\hline \multirow{4}{*}{ Pamengpeuk } & Semai & 2,75 & Sedang & 6,09 & Tinggi & 0,76 & Tinggi & 0,076 & Rendah \\
\hline & Pancang & 2,62 & Sedang & 3,65 & Sedang & 0,91 & Tinggi & 0,082 & Rendah \\
\hline & Tiang & 2,90 & Sedang & 5,82 & Tinggi & 0,99 & Tinggi & 0,06 & Rendah \\
\hline & Pohon & 2,73 & Sedang & 6,83 & Tinggi & 0,77 & Tinggi & 0,094 & Rendah \\
\hline \multirow{4}{*}{ Leles } & Semai & 2,12 & Sedang & 4,25 & Sedang & 0,63 & Tinggi & 0,143 & Rendah \\
\hline & Pancang & 2,12 & Sedang & 4,28 & Sedang & 0,39 & Sedang & 0,114 & Rendah \\
\hline & Tiang & 0,39 & Rendah & 1,71 & Rendah & 0,16 & Rendah & 0,662 & Tinggi \\
\hline & Pohon & 0,81 & Rendah & 2,68 & Rendah & 0,31 & Sedang & 0,537 & Tinggi \\
\hline
\end{tabular}

Tabel 5 Pola penyebaran jirak

\begin{tabular}{clccccc}
\hline No & Lokasi & Id & Mu & Mc & Ip & Pola Penyebaran \\
\hline 1 & Blok Pamengpeuk & 1.447 & 0.385 & 1.809 & 0.277 & Mengelompok \\
2 & Blok Jirak & 2.679 & -0.657 & 3.195 & 0.382 & Mengelompok \\
\hline
\end{tabular}


kurang terganggu (Kacholi 2014). Hal demikian tidak terjadi pada Blok Leles yang memiliki nilai sangat tinggi pada kelas diameter $20-30 \mathrm{~cm}$ namun menurun secara drastis pada kelas diameter selanjutnya.

\section{Struktur Vertikal}

Struktur vertikal hutan dapat diketahui dengan melihat sebaran tinggi tegakannya. Setiap individu yang ditemukan dikelompokkan berdasarkan kelas tinggi. Menurut Kusmana et al. (2009), Pengelompokan ini sesuai dengan stratum pohon, yaitu stratum A (Stratum paling atas dengan ketinggian $>30 \mathrm{~m})$, stratum B (2030m), dan stratum C (4-20m).

Berdasarkan Gambar 4 dapat dikatakan bahwa kelas tinggi pada Blok Leles dan Blok Pamengpeuk dibagi menjadi 3 strata, yaitu stratum C (4-20 m), stratum B (20$30 \mathrm{~m})$, dan stratum tertinggi yaitu stratum A (>30 m). Kelas tinggi 4-20 m memiliki nilai paling besar pada kedua lokasi dan nilai tersebut berbanding terbalik dengan meningkatnya kelas tinggi. Penurunan jumlah pohon per hektar ini dapat disebabkan oleh berbagai macam faktor seperti persaingan untuk mendapatkan unsur hara, air, dan cahaya sehingga terdapat jenis-jenis tertentu yang lebih berkuasa (Soerianegara dan Indrawan (2005). Pohon yang berumur cukup tua dan dari jenis pohon klimaks saja yang dapat mencapai stratum A, jenis pohon tertentu membutuhkan waktu yang lebih lama untuk mencapai stratum A dibandingkan waktu yang dibutuhkan untuk mencapai stratum B. Melimpahnya individu pada stratum $\mathrm{C}$ menandakan terjaminnya kelestarian hutan di area ini di masa mendatang karena terdapat peluang besar individu permudaan tumbuhan dapat berkembang menjadi pohon dewasa (Meyer dan Anderson 1952).

\section{SIMPULAN DAN SARAN}

\section{Simpulan}

Hutan di Resort Kawah Ratu TNGHS memiliki pola penyebaran secara mengelompok baik pada Blok Leles maupun Blok Pamengpeuk. Kerapatan jenis jirak di blok Pamengpeuk lebih besar pada semua tingkat pertumbuhan dibandingkan kerapatan di Blok Leles. Kerapatan jirak pada Blok Pemengpeuk membentuk kurva "J" terbalik yang menandakan terdapatnya peluang

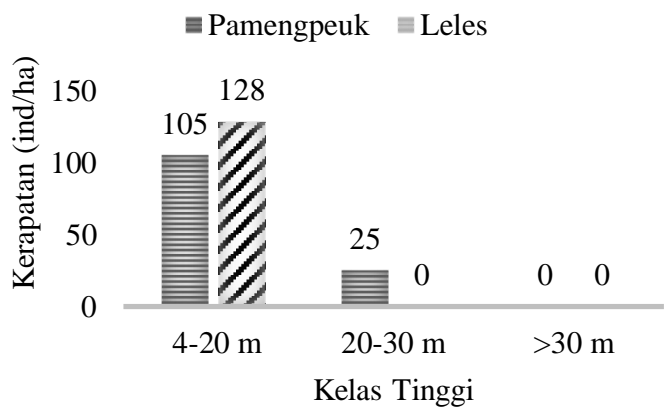

Gambar 4 Struktur vertikal pada tingkat pohon di lokasi penelitian besar permudaan dapat berkembang menjadi pohon dewasa sehingga kelestarian hutan terjaga.

\section{Saran}

Penelitian yang dilakukan masih kekurangan informasi mengenai pengaruh dari faktor-faktor yang menguntungkan bagi jenis jirak sehingga mengelompok pada kawasan tertentu seperti, faktor lingkungan berupa iklim, suhu, tanah udara, kelembapan, kelerengan, dan juga faktor biotik seperti pengaruh dan interaksi dengan jenis lain di sekitar.

\section{DAFTAR PUSTAKA}

Anggana AF, Cahyono SA, Lastiantoro CY. 2019. Keanekaragaman hayati di lahan rehabilitasi Taman Nasional Meru Betiri dan implikasi kebijakannya: kasus Desa Wonoasri. Jurnal Ilmu Lingkungan 17(2): 283-290.

Carolyn RD, Baskoro DPT, Prasetyo LB. 2013. Analisis degradasi untuk penyusunan arahan strategi pengendaliannya di Taman Nasional Gunung Halimun Salak Provinsi Jawa Barat. Globe. 15(1):39-47.

Departemen Kehutanan. 1999. Undang-Undang No. 41 Tentang Kehutanan. Jakarta (ID): Departemen Kehutanan.

Gustiani A. 2015. Pola penyebaran jenis kapasan kuning (Thespesia lampas Dalz and Gibs) di Savana Bekol Taman Nasional Baluran [skripsi]. Bogor (ID): Institut Pertanian Bogor.

Hanum SF. 2012. Pemanfaatan Pohon Loba (Symplocos fasciculata Zoll.) sebagai Pembangkit Warna Alam pada Kerajinan Tenun Di Desa Pejeng, Tampak Siring, Gianyar, Bali. Berita Biologi 11(3): 367-372.

Irfani E. 2016. Pola penyebaran dan regenerasi jenis saninten (Castanopsis argentea Blume) di Resort Selabintana Taman Nasional Gunung Gede Pangrango [Skripsi]. Bogor: Institut Pertanian Bogor.

Ismaini L, Lailati M. 2015. Analisis komposisi dan keanekaragaman tumbuhan di Gunung Dempo, Sumatera Selatan. Di dalam: Rustandi, Sunandar D, editor. Prosiding Seminar Nasional Biodiversitas Indonesia; 2015 Mei 15; Cianjur, Indonesia. Cianjur (ID): UPT Balai Konservasi Tumbuhan Kebun Raya Cibodas, Lembaga Ilmu Pengetahuan Indonesia (LIPI). Hlm: 1397-1402.

Istomo, Afnani M. 2014. Potensi dan sebaran jenis meranti (Shorea spp.) pada kawasan lindung PT Wana Hijau Pesaguan, Kalimantan Barat. Jurnal Silvikultur Tropika. 5(3):196-205.

Istomo. 1994. Bahan Bacaan Ekologi Hutan: Lingkungan Fisik Ekologi Hutan: Proses dan Struktur Tanah. Bogor (ID): Laboratorium Ekologi Hutan, Fakultas Kehutanan IPB.

Jongjitvimol T, Boontawon K, Wattanachaiyingcharoen W, Deowanish S. 2005. Nest dispersion of a stingless bee species (Trigona collina Smith 1857) Apidae, Meliponinae in a mixed deciduous forest 
in Thailand. The Natural History Journal of Chulalongkorn University 5(2): 69-71.

Kacholi DS. 2014. Analysis of structure and diversity of the Kilengwe Forest in the Morogoro Region, Tanzania. International Journal of Biodiversity. 2014:516840.

Krebs JC. 1978. Ecology: The Experimental Analysis of Distribution and Abundance. New York (US): Harper and Rowl Publisher.

Magurran AE. 1988. Ecological Diversity and Its Measurement. Australia (AU) :Great Britanian Pr.

Meyer BS, Anderson DB. 1952. Plant Physiology. New York (US): D Van Nostrand Company Inc.

Morisita M. 1959. Measuring of the dispertion of individuals and analysis of the distributional patterns. Memories of the Faculty of Science, Kyushu University, Series E (Biology) 2(4): 215 235.

Mueller-Dombois D, Ellenberg H. 1974. Aims and Methods of Vegetation Ecology. New York (US): John Wiley \& Sons.
Nooteboom HP. 1999. Symplocos Jacq. Dalam: RHMJ Lemmens dan N Wulijarni-Soetjipto (Penyunting). Sumber Daya Nabati Asia Tenggara No. 3: Tumbuh-Tumbuhan Penghasil Warna dan Tanin. Balai Pustaka dan Prosea Indonesia, Jakarta dan Bogor.

Pamungkas D. 2013. Teknik Skarifikasi Biji Loba Manu (Symplocos fasciculata). Tekno Hutan Tanaman 6(2): 65-70.

Soerianegara I, Indrawan A. 2005. Ekologi Hutan Indonesia. Bogor (ID): Laboratorium Ekologi Hutan, Fakultas Kehutanan IPB.

Tudjuka K, Ningsih S, Toknok B. 2014. Keanekaragaman jenis tumbuhan obat pada kawasan hutan lindung di Desa Tindoli Kecamatan Pamona Tenggara Kabupaten Poso. Warta Rimba 2(1): 120-128.

Utomo B. 2013. Peran Celah Antar Tajuk Tegakan dan Seed Bank Tanah Terhadap Regenerasi Hutan. Jurnal Agrista. 17(2): 78-85. 